\title{
Diagnostics of a persistence property for quotations dynamics on high-tech stock markets
}

\author{
Nataliia Maksyshko ${ }^{1, *}$, and Oksana Vasylieva ${ }^{1}$ \\ ${ }^{1}$ Zaporizhzhia National University, Department of Economic Cybernetics, 66, Zhukovskogo str., Zaporizhzhia, 69600, Ukraine
}

\begin{abstract}
The research purpose is diagnosis of the persistence property for the stock quotes time series of leading companies belonging to the high-tech sector: Apple Inc., Microsoft Corporation and Samsung Electronics Co. The persistence property or the trend-stability of the time series is crucial meaning for the investor. As a result of the application of the R $\backslash \mathrm{S}$-analysis, it is proved that the stock quotations dynamics of these companies have the persistence property. Also, the method of sequential $\mathrm{R} \backslash \mathrm{S}$ analysis is applied: the leading characteristics of the long-term memory are discovered, which makes it possible to carry out a comparative analysis of their predictability. It is found that the time series of profitability do not have the properties of persistence. However, the tests for diagnostic of a deterministic chaos reveal the appearance of the persistence property in the time series of "delayed" profitability. The obtained results allows to state the fractal nature for the time series of quotations, while the characteristics of the persistence (depth of memory) determined by the research can be useful to the investor in terms of the investment instrument choice and the investment horizon as well as can be used in selecting the parameters for a forecasting model.
\end{abstract}

\section{Introduction}

Stock markets are one of the most important components of the global financial system. Created for communication between business and investors, they are now indicators of the world economy state as a whole.

An overview of stock markets and their stock segments suggests that, despite the overall positive dynamics of the world stock market, there is a cyclical nature changes in the economic performance of national stock markets and trading platforms not only in developing countries but also in highly developed countries of the world. So it can be noted that the stock market again fell at the end of 2018. Hence, before investing in certain stock market instruments, investors need to make a detailed analysis of this solution, consider all the pros and cons.

In order to conduct well-considered investment actions and make effective decisions in managing a portfolio of securities, an investor who wishes to invest should take into account a number of factors that determine the level of risk and the list of expected results and allow making a well-balanced conclusion. At the same time it is necessary to note the significant role by modern information technologies and economic and mathematical methods for modeling processes and stock markets dynamics.

Traditionally, linear dynamics methods were used to assess the dynamics of stock markets [1-3], these methods are actively being used now [4-10]. However, in the 1990s, the nonlinear paradigm, which is represented by the hypothesis of the fractal market, began to develop actively $[11,12]$. This direction became widespread and was used in works $[13,14]$. Within this paradigm it was discovered that for many time series, reflecting the development processes dynamics in the socio-economic and other spheres of human activity inherent a long-term memory or the property of persistence $[15,16]$. Its presence means that observations are not independent. Each observation has a memory of the events that precede it. And that is not a short-term memory, often called "Markov's" one. This is a different type of memory - a long-term memory, theoretically it is stored permanently. Recent events have an impact larger than distant events, but the residual effect of each event is always tangible.

The persistence property or trend-stability of the time series is positive for the investor. The presence of the persistence property and, accordingly, the effect of longterm memory in the time series of the investment instrument, on the one hand, provides for better predictability of its dynamics, and, on the other hand, reduces the risks of accidental changes within the planning horizon. The purpose of this work is to diagnose the presence of the persistence properties and to identify the characteristics of long-term memory in the time series of highly liquid instruments in the high-tech segment of the stock market to obtain practical recommendations on the possibility forecasting the dynamics of these securities.

\section{Materials, methods and results}

The input data of the work were selected the value of stock quotes companies, which are American blue chips:

\footnotetext{
*Corresponding author: maxishko@ukr.net
} 
Apple Inc. (AAPL) and Microsoft Corporation (MSFT), and the main Apple's rival - South Korean company Samsung Electronics Co (SSUN). These companies belong to the high-tech sector, according to estimates Forbes [15] they are among the 20 largest companies in the world and have gilt-edged security [16]. The time series length is the last 10 years period - from 2009 to $2018[17,18]$.

\subsection{Investigation of stock quotes time series}

Consider three time series (TS) of stock quotes Apple.Inc. (AAPL), Microsoft Corporation (MSFT) and Samsung Electronics Co (SSUN) for the period from 2009 to 2018 :

$$
V(i)=\left\langle v_{t}(i)\right\rangle, t=\overline{1,2516} ;
$$

where $i \in\{$ AAPL, MSFT, SSUN\}.

The visualization of the Apple.Inc., Microsoft Corporation and Samsung Electronics Co stock quotes dynamics is presented in the figure 1 .

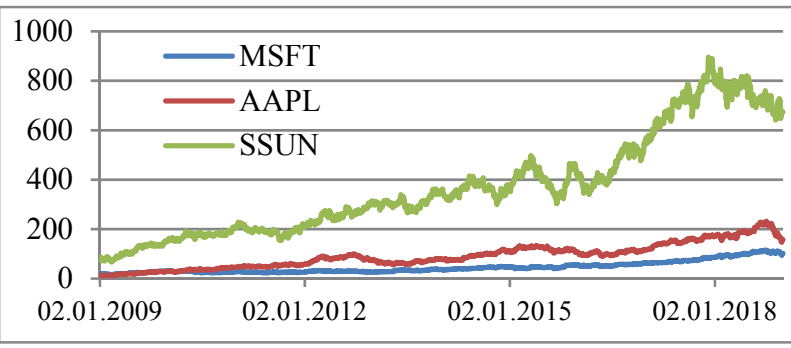

Fig. 1. Stock quotes dynamics of Apple.Inc. - V(AAPL), Microsoft Corporation - V(MSFT) and Samsung Electronics Co securities - V(SSUN) for the period from 2009 to 2018.

One of the most common indicators that diagnoses memory in time series, and, consequently, nonlinearity is the Hurst exponent.

If the system for a sufficiently long period of time shows a high value of the Hurst exponent $H$, this indicates interrelated events. As a measure of interrelated events, it is known there is a correlation coefficient. The influence the present-day to the future can be given by the following correlation ratio [11]:

$$
C=2^{2 H-1}-1,
$$

where $\mathrm{C}$ - measure of correlation, $H$ - Hurst exponent.

If $H \in(0,5 ; 1]$, then TS is persistent or trendresistant $[11,12]$ and is characterized by the effect of long-term memory. The events are all the more correlated, the closer the value of $\mathrm{H}$ to 1 ( $\mathrm{C}$ is also close to one or to $100 \%$ correlation according to (1)).

We apply $\mathrm{R} \backslash \mathrm{S}$-analysis $[11,12]$ to the output time series. The results of R $\backslash \mathrm{S}$-analysis are shown in Table 1. This indicates the existence of the persistence properties in the output time series. This fact is also confirmed by the results of a mixing test (Table 1). According to its results, the Hurst exponents for the mixed time series are close to 0.5 .
Table 1. Hurst exponents for the time series and mixed time series of Apple Inc., Microsoft Corporation and Samsung

Electronics Co stock quotations from 2009 to 2018.

\begin{tabular}{|c|c|c|}
\hline V (i) & $H$ & $H_{\text {mixed }}$ \\
\hline V (AAPL) & 0.965 & 0.587 \\
\hline V (MSFT) & 0.953 & 0.539 \\
\hline V (SSUN) & 0.964 & 0.571 \\
\hline
\end{tabular}

To avoid false judgments, let's take into account the experience of the previous researches on the particularities of calculating the Hurst exponent: with an increase in the length of a series, the Hurst exponent tends to be overestimated. To take into account this feature, we calculate the Hurst exponent for the last year from the study period:

$$
\mathrm{V}^{2018}(\mathrm{i})=\left\langle\mathrm{v}_{\mathrm{t}}(\mathrm{i})\right\rangle, \mathrm{t}=\overline{1,251}
$$

where $\mathrm{i} \in\{$ AAPL, MSFT, SSUN\}.

As a result of calculations, we get the Table 2 .

Table 2. Hurst exponents for the time series and mixed time series of Apple Inc., Microsoft Corporation and Samsung Electronics Co stock quotations per 2018

\begin{tabular}{|l|c|c|}
\hline $\mathrm{V}(\mathrm{i})$ & $H$ & $H_{\text {mixed }}$ \\
\hline $\mathrm{V}$ (AAPL) & 0.912 & 0.605 \\
\hline $\mathrm{V}$ (MSFT) & 0.91 & 0.545 \\
\hline $\mathrm{V}$ (SSUN) & 0.904 & 0.631 \\
\hline
\end{tabular}

The obtained values are confirmed by our assumption that the stock quotes time series (TS) of three companies have the property of persistence, and, as a result, the presence of long-term memory.

However, the Hurst exponent characterizes the behavior of the time series in the whole, but does not allow quantifying the memory depth of the time series. Because over time, this characteristic may change, so we do not deal with a uniquely determined value, but with a value that is characterized by uncertainty: the depth of memory can take some value from the set of possible values. For its description and definition, we use the sequential $R \backslash S$-analysis method specified in [19]. The result of this method is the construction of a memory depth fuzzy set:

$$
L(i)=\left\{(l, \mu(l)), l \in L^{0}\right\}
$$

Graphical representations of the memory depth fuzzy set for each time series are shown in the Figure 2.

The value of the membership function $\mu(1)$ determines the degree of belonging of the natural number 1 ("depth 1") to the fuzzy set L(i). Therefore, to characterize and compare the behavior of time series, it is important to establish, firstly, the memory depth that is most commonly found in the time series, and secondly, the range of time slices 1 for which the trend-stability of the series is typical (the value of the membership function 1 exceeds 0.6). This information is presented in Table 3. 


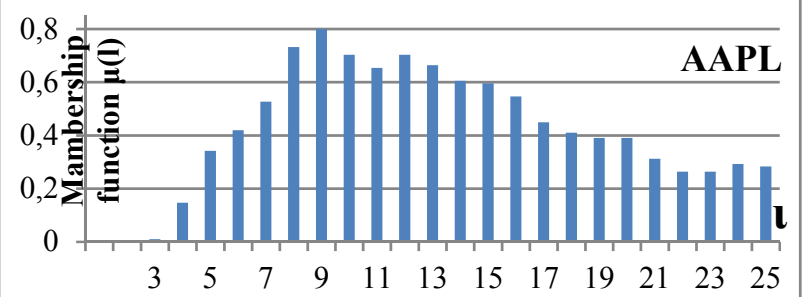

a)

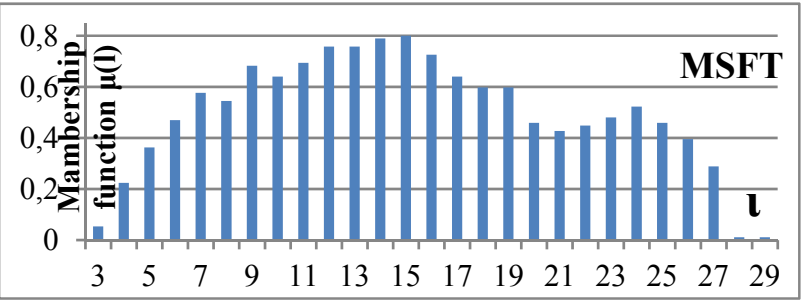

b)

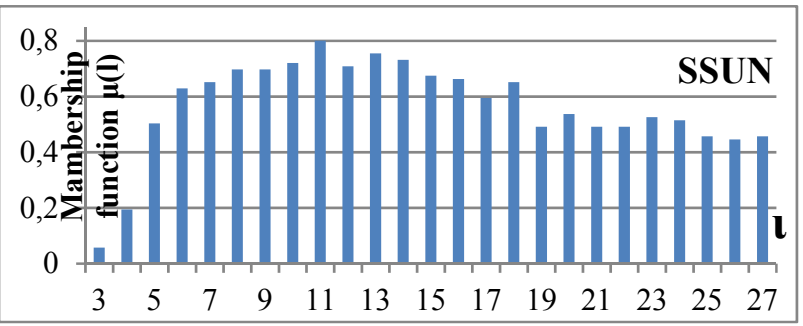

c)

Fig. 2. Fuzzy set L(i) of memory depths for the time series of Apple Inc. (a), Microsoft Corporation (b) and Samsung Electronics Co (c) securities.

Table 3. Information about the fuzzy set of memory depths for stock quotations.

\begin{tabular}{|c|c|c|}
\hline V (i) & The range $l$, if $\mu(l) \geq 0,6$ & $\begin{array}{c}\text { Memory depth } l \\
\text { with the largest } \mu(l)\end{array}$ \\
\hline V(AAPL) & $8-15$ days & 9 days \\
\hline V(MSFT) & $9-17$ days & 15,14 days \\
\hline V(SSUN) & $6-18$ days & 11 days \\
\hline
\end{tabular}

Thus, it is found that all three time series have close values of memory depth. However, if for AAPL and SSUN securities they are 9 and 10,11 days respectively, then MSFT is 15 days. At the same time for this time series (MSFT) there is the smallest range of depth distribution - from 9 to 17 days. The obtained results allow us to assert that the long-term influence of the previous values of a series on its subsequent ones exists. And in comparison with other three securities the most stable time series is $\mathrm{V}(\mathrm{MSFT})$. This can be used as an advantage in assessing the risk of investing, predictability of its outcome and, consequently, to determine the investment horizon.

Thus, in analyzing stock quotations of selected companies, their fractality was established, which enabled the use of discrete nonlinear dynamics methods to obtain important characteristic indicators of the dynamics of these time series.

\subsection{Profitability time series of stock quotations}

In the analysis of stock quotations on the financial market it is accepted to work not only with the sequence of absolute prices, but with the sequence of relative changes, that is, the yield or profitability of the security.

The sequence of relative prices has certain advantages over the sequence of prices.

First, the transformation of the price sequence into the sequence of relative changes allows for greater comparability of different assets.

Secondly, for the sequence of relative changes, the average and variance are more stationary than the average and variance of the sequence of absolute prices values [20, 21].

We find out the question of the persistence properties availability for the time series of the above financial instruments (stock quotations).

Consider the profitability TS calculated by the formulas:

$$
\begin{gathered}
P(i)=\left\langle p_{t}(i)\right\rangle, \\
p_{t}(i)=\frac{\left(v_{t}(i)-v_{(t-1)}(i)\right)}{v_{(t-1)}(i)} * 100 \%,
\end{gathered}
$$

where $\mathrm{v}_{\mathrm{t}}(\mathrm{i})$ - the quotation of the investment instrument at a day $\mathrm{t}, \mathrm{i} \in\{$ AAPL, MSFT, SSUN $\}$.

The obtained time series of profitability are checked for the existence of persistence properties using the Hurst exponent. The Hurst exponents for stock quotations profitability are close to 0.5 (Table 4), indicating the random nature of the changes in the increment of quotations and the absence of internal ties between events.

Table 4. The Hurst exponents for the profitability time series depending on the value of lag.

\begin{tabular}{|c|c|c|c|c|c|c|c|c|}
\hline \multirow{2}{*}{$\mathrm{i}$} & \multicolumn{8}{|c|}{ The Hurst exponent for $\mathrm{P}_{\mathrm{S}}(\mathrm{i})$} \\
\cline { 2 - 9 } & $\mathrm{S}=1$ & $\mathrm{~S}=5$ & $\mathrm{~S}=10$ & $\mathrm{~S}=15$ & $\mathrm{~S}=18$ & $\mathrm{~S}=21$ & $\mathrm{~S}=25$ & $\mathrm{~S}=42$ \\
\hline AAPL & 0,58 & 0,71 & 0,77 & $\mathbf{0 , 8 0}$ & $\mathbf{0 , 8 2}$ & $\mathbf{0 , 8 3}$ & $\mathbf{0 , 8 4}$ & $\mathbf{0 , 8 7}$ \\
\hline MSFT & 0,55 & 0,699 & 0,76 & 0,79 & $\mathbf{0 , 8 0}$ & $\mathbf{0 , 8 1}$ & $\mathbf{0 , 8 3}$ & $\mathbf{0 , 8 5}$ \\
\hline SSUN & 0,54 & 0,66 & 0,73 & 0,77 & 0,78 & $\mathbf{0 , 8 0}$ & $\mathbf{0 , 8 1}$ & $\mathbf{0 , 8 4}$ \\
\hline
\end{tabular}

The obtained Hurst exponents show there are no signs of fractality in the selected time series. In this way, families of profitability time series with a certain lag were constructed and investigated [22].

The time series of the "delayed" profitability are constructed by the formula:

$$
p_{t}^{S}(\mathrm{i})=\frac{\left(\mathrm{v}_{\mathrm{t}}(\mathrm{i})-\mathrm{v}_{(\mathrm{t}-\mathrm{s})}(\mathrm{i})\right)}{\mathrm{v}_{(\mathrm{t}-\mathrm{S})}(\mathrm{i})} * 100 \%,
$$

where $\mathrm{v}_{\mathrm{t}}(\mathrm{i})$ - the quotation of the investment instrument at a day $\mathrm{t} ; \mathrm{s}-$ is a lag value.

Then profitability time series is equal to:

$$
\mathrm{P}_{\mathrm{s}}(\mathrm{i})=\left\langle p_{t}^{S}(i)\right\rangle,
$$

where $\mathrm{i} \in\{$ AAPL, MSFT, SSUN $\}$.

However, the question remains: how quickly this property acquires the time series of so-called "delayed profitability". 
The character of the profitability dynamics varies depending on the magnitude of the time lag (Table 4) and, as it grows, the time series acquire the properties of persistence (the property of memory).

The graphic representation of the Hurst exponent dependence on the lag is shown in Figure 3:

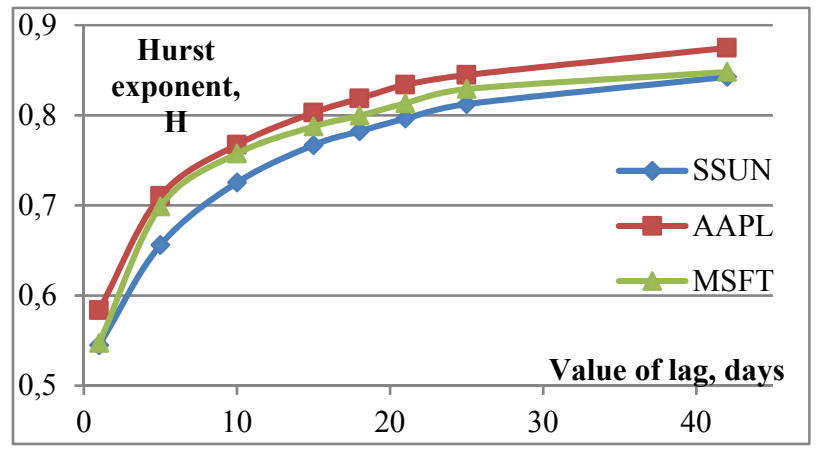

Fig. 3. Hurst exponent depending on the value of lag.

Figure 5 shows that the Hurst exponent grows parabolic with increasing lag magnitude. The persistent one is that time series, if its Hurst exponent equal to or greater than 0,8 . Moreover, the growth rate of $\mathrm{H}$ in the profitability of different securities is different: for AAPL this lag is 15 days, for MSFT - 18 days, for SSUN - 21 days.

For the received persistent time series we carry out their diagnostics for the presence in their structure of deterministic chaos. Since the results of the AAPL, MSFT, and SSUN profitability are similar, we consider the results of the tests for AAPL stock quotations. Figure 4 shows the profitability TS for Apple shares with the lag 1 (a) and 15 (b).

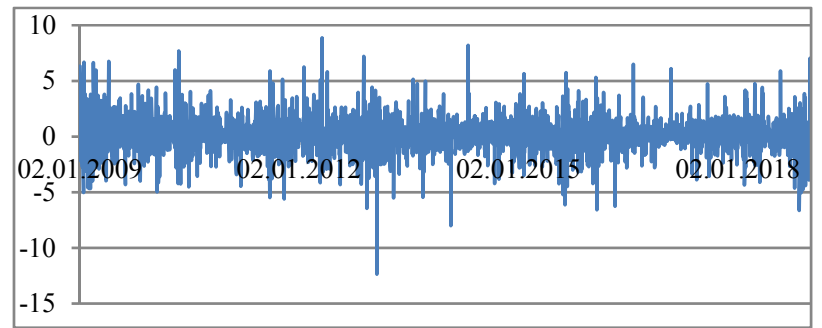

a)

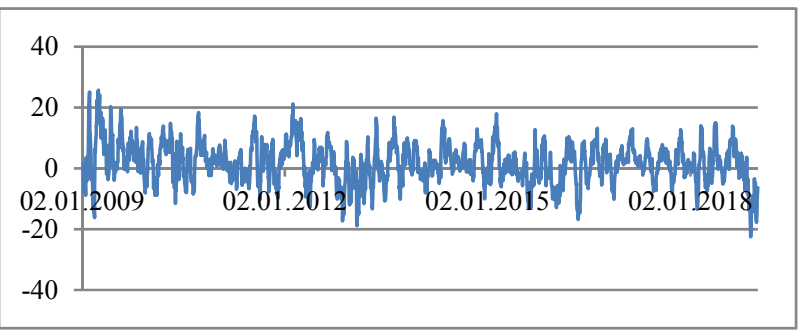

b)

Fig. 4. Dynamics of profitability time series for Apple Inc. (AAPL) with: a) lag 1 ; b) lag 15.

Figure 4 shows how the time series structure changes and how periods of growth or decline in profitability appear. Moreover, not one of the time series has any signs of stationary behavior, this means the expediency of further diagnostics by the methods of deterministic chaos [23].

At the next stage, pseudophase spaces are constructed and drift attractor' tests are performed. Graphic representation is shown in Figure 5.

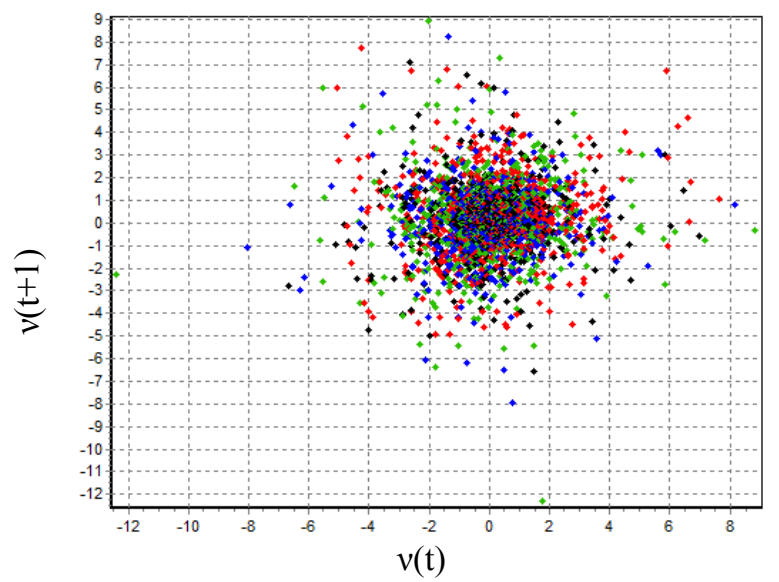

a)

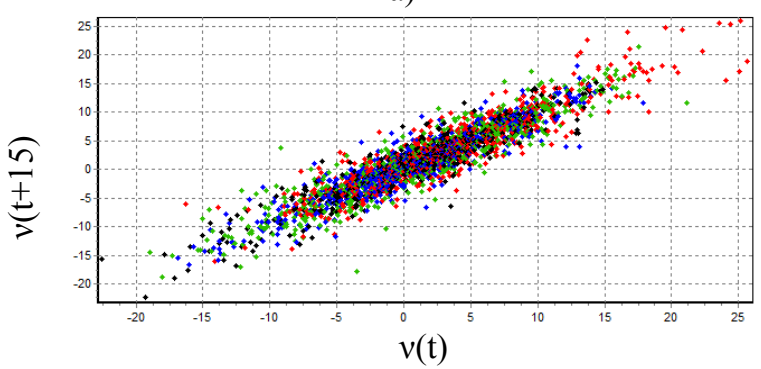

b)

Fig. 5. Pseudo-phase spaces with tests on a drifting attractor for profitability time series of AAPL with: a) lag $1-\mathrm{P}_{1}$ (AAPL); b) lag $15-\mathrm{P}_{15}$ (AAPL).

The construction of the pseudophase space allows to establish the relationship between the events of the series in time for the delayed profitability and to put forward the hypothesis of the attractor presence. Conversely, the time series of the AAPL profitability with the lag 1 shows accumulation near the point $(0,0)$ with a random deviation from it. That is, for the time series of profitability $\mathrm{P}_{1}$ (AAPL), the hypothesis regarding the presence of such deterministic chaos features as a drifting attractor or joker is rejected, and events of the time series are defined as independent of each other.

Figure 6 shows a graphical representation of the Gilmore test [24].

The Gilmore test demonstrates changes in the dynamics of the two time series $\mathrm{P}_{1}$ (AAPL) and $\mathrm{P}_{15}$ (AAPL) from random to deterministic chaos. Figure 6 b) shows the presence of close trajectories, as well as empty sections and diagonal bands, which may indicate an interval joker.

Thus, the resulting time series of delayed profitability acquire characteristics of fractal dynamics (deterministic chaos) and become suitable for analysis by nonlinear dynamics methods. Using the sequential $\mathrm{R} \backslash \mathrm{S}$-analysis method [19] we obtain the values of the depth memory, which characterizes the ranges of the trend-stability of the time series (Figure 7). 


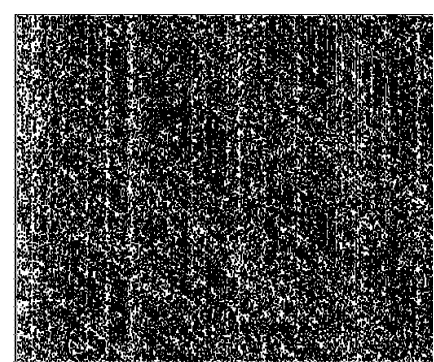

a) b)

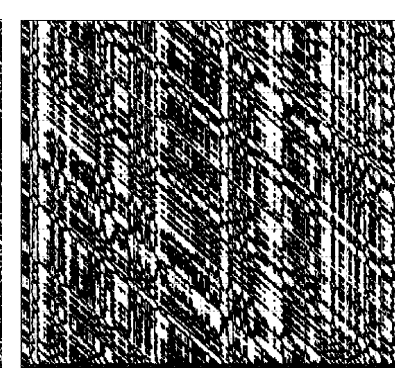

Fig. 6. Gilmore graphic test for profitability time series of AAPL with: a) lag1 - $\mathrm{P}_{1}$ (AAPL); b) lag $15-\mathrm{P}_{15}$ (AAPL).

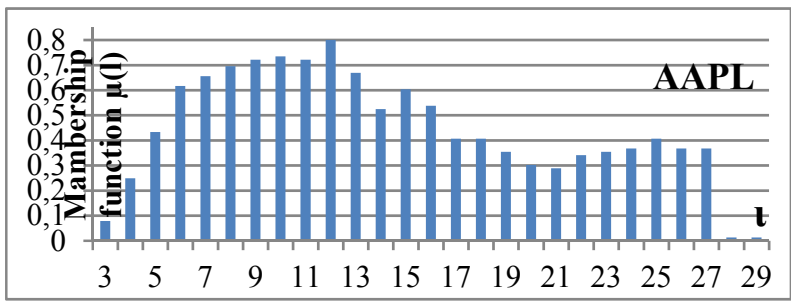

a)

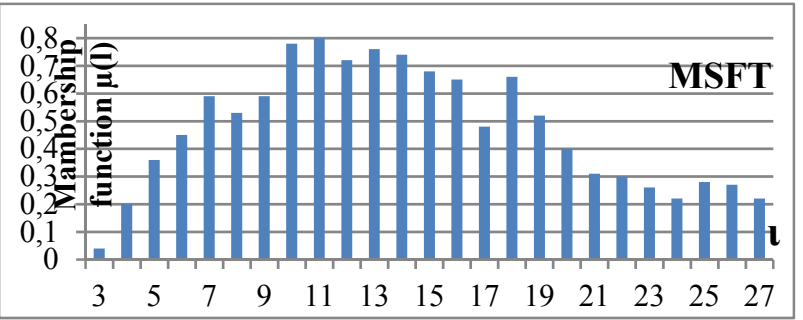

b)

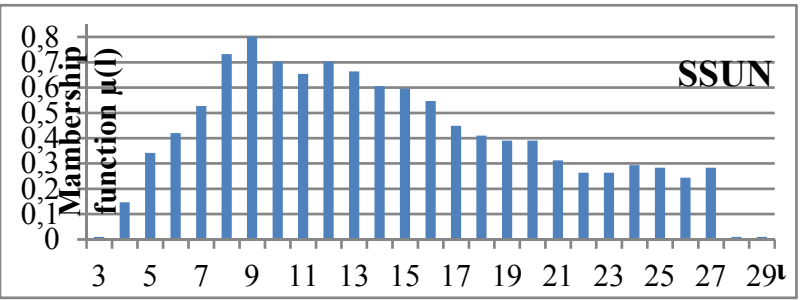

c)

Fig. 7. Fuzzy set of memory depths for the profitability time series of: a) AAPL with lag 15 days; b) MSFT with lag 18 days; c) SSUN with lag 21 days.

Table 5 shows the memory depth $l$ with the largest value of the membership function $\mu(l)$ and the time period for which the membership function $\mu(l)$ exceeds the value of 0.6 .

Table 5. Information about the fuzzy set of memory depths for the delayed profitability time series.

\begin{tabular}{|c|c|c|}
\hline $\mathrm{P}_{\mathrm{s}}(\mathrm{i})$ & $\begin{array}{c}\text { The range } l, \\
\text { if } \mu(l) \geq 0,6\end{array}$ & $\begin{array}{c}\text { Memory depth } l \\
\text { with the largest } \mu(l)\end{array}$ \\
\hline $\mathrm{P}_{15}$ (AAPL) & $6-13,15$ & 12 \\
\hline $\mathrm{P}_{18}$ (MSFT) & $10-16$ & 11 \\
\hline $\mathrm{P}_{21}$ (SSUN) & $8-14$ & 9 \\
\hline
\end{tabular}

From table 5 it follows that the most persistent is the time series $\mathrm{P}_{15}(\mathrm{AAPL})$, despite the least time lag $\mathrm{s}$.

\section{Conclusions}

The persistence property or trend-stability of the time series is crucial for the investor. The presence of persistence and, accordingly, the effect of long-term memory in the time series of the investment instrument, on the one hand, provides for better predictability of its dynamics, and, on the other, reduces the risk of accidental changes within the planning horizon. In this work, a diagnostic of the persistency are conducted for the stock quotations time series of Apple Inc., Microsoft Corporation, and Samsung Electronics Co., Ltd.

As a result of the application of the normalized Hurst range ( $\mathrm{R} \backslash \mathrm{S}$-analysis), it is proved that the stock quotations dynamics of these companies have the persistence property. Applying the sequential $\mathrm{R} \backslash \mathrm{S}$ analysis method, the leading characteristics of the longterm memory are discovered, it makes possible to carry out a comparative analysis of their predictability.

At the next stage, time series of stock returns (the profitability time series) were studied. It was found that the profitability time series do not have the properties of persistence, and the values of profitability are independent of each other. However, the use of the drift attractor test and the Gilmore test, as well as R\Sanalysis, allows revealing the appearance of the persistence property in the "delayed" profitability time series. For persistent time series of profitability, fuzzy sets of memory depths were built and time intervals for which memory is characteristic were revealed.

The set of results obtained allows us to assert the fractal nature of the quotations time series, while the characteristics of the persistence (depth of memory) determined by the research can be useful to the investor in terms of the investment instrument choice and the investment horizon as well as can be used in selecting the parameters of the forecasting model.

\section{References}

1. Fama, E.: Random walks in stock market prices. Financial Analysts Journal. 21(5), 55-59 (1965)

2. Fama, E.: Efficient capital markets: a review of theory and empirical work. J. of Finance. 25, 383417 (1970)

3. Fama, E.: Efficient Capital Markets: 2. J. of Finance. 46(5), 1575-1617 (1991)

4. Gümüs, F., Zeren, F.: Analyzing the Efficient Market Hypothesis with the Fourier Unit Root Test: Evidence from G-20 Countries. Ekonomski horizonti. 16(3), 225-237 (2014)

5. Gupta, N., Gedam, A.: Testing of Efficient Market Hypothesis: a study on Indian Stock Market. J. of Business and Management. 16(8), 28-38 (2014)

6. Chen, C., Metghalchi, M.: Weak form market efficiency: Evidence from the Brazilian stock market. Intern. J. of Economics and Finance. 4(7), 22-32 (2012)

7. Ananzeh, I.E.N.: Testing the weak form efficient market hypothesis: Empirical evidence from Jordan. 
Intern. Business and Management. 4(2), 119-123 (2014)

8. Ogbulu, O.M.: Weak-form market efficiency, estimation interval and the Nigerian stock exchange: empirical evidence. Intern. Academy of Business Review. 3(1), 42-61 (2016)

9. Onali, E., Goddard, J.: Are European equity markets efficient? new evidence from fractal analysis. International Review of Financial Analysis 20, 5967 (2011)

10. Singh, S.K., Singh, K.B.: Market reaction around mergers and acquisitions announcements in India: a test of Efficient Market Hypothesis. Gurukul Business Review-Gbr. 13, 37-41 (2017)

11. Peters, E.: Chaos and order in the capital markets $-\mathrm{a}$ new view of cycles, prices, and market volatility. John Wiley \& Sons, Inc., New York (1991)

12. Peters, E.: Fractal market analysis. Applying chaos theory to investment and analysis. John Wiley \& Sons, Inc., New York (1994)

13. Wang, X.Y., Lei, T., Liu, Z., Wang, Z.B.: Longmemory behaviour analysis of china stock market based on Hurst exponent. Paper presented at the 29th Chinese Control And Decision Conference (CCDC), Peoples R China, Chongqing, 28-30 May 2017

14. Erokhin, S., Roshka, O.: Application of fractal properties in studies of financial markets. Paper presented at the International Scientific Conference on Business Technologies for Sustainable Urban Development (SPbWOSCE), Peter Great Saint Petersburg Polytechn University, Inst Ind Management Econ \& Tr, St Petersburg, 20-22 December 2017

15. Forbes Global 2000: The world's largest public companies. June 6, 2018. https://www.forbes.com/global2000/\#3e840633335d (2018). Accessed 05 March 2019

16. Financial portal Nasdaq. https://www.nasdaq.com/investing/glossary/b/bluechip-company (2018). Accessed 05 March 2019

17. Yahoo Finance. https://finance.yahoo.com/ (2018). Accessed 01 Feb 2019

18. Global financial portal Investing.com. https://www.investing.com (2018). Accessed $01 \mathrm{Feb}$ 2019

19. Maksyshko, N.K.: Modeliuvannia ekonomiky metodamy dyskretnoi nelinijnoi dynamiky (Modeling of economics by methods of discrete nonlinear dynamics). Polihraf, Zaporizhzhia (2009)

20. Bidyuk, P.I.: Prognosis of volatility of financial processes for alternative models. Sciences. Visti NTUU “KPI”. 6, 36-45 (2012)

21. Borimsky, Yu.S.: Algorithms of the investment portfolio of the investment and the assignment of active parts in the investment capital. Sciences. Visti NTUU "KPI". 3, 5-10 (2009)
22. Vasylieva, O.V., Maksyshko, N.K.: Research of dynamics in the gold market: the investment aspect. Investytsiyi: praktyka ta dosvid. 19, 8-15 (2017)

23. Sergeeva, L.N.: Nelineynaya ekonomika: modeli i metody (Nonlinear Economy: models and methods). Polihraf, Zaporizhzhia (2003)

24. Gilmore, C.G.: A new test for chaos. J. of economic behavior and organization. 22, 209-237 (1993) 